\title{
PERFORMANCE ANALYSIS OF THE RECENT ROLE OF OMSA APPROACHES IN ONLINE SOCIAL NETWORKS
}

\author{
J. Ashok Kumar ${ }^{1}$, S. Abirami ${ }^{2}$, S. Murugappan ${ }^{3}$ \\ Research Scholar ${ }^{1}$, Assistant Professor ${ }^{2}$, Associate Professor ${ }^{3}$ \\ ${ }^{1,2}$ Department of Information Science and Technology, \\ Anna University, Chennai, India \\ jashokkumar83@gmail.com, abirami@annauniv.edu \\ ${ }^{3}$ Department of Computer Science, \\ Tamil Nadu Open University, Chennai, India \\ drmryes@gmail.com
}

\begin{abstract}
In this emerging trend, it is necessary to understand the recent developments taking place in the field of opinion mining and sentiment analysis (OMSA) as part of text mining in social networks, which plays an important role for decision making process to the organization or company, Government and general public. In this paper, we present the recent role of OMSA in Social Networks with different frameworks such as data collection process, text pre-processing, classification algorithms, and performance evaluation results. The achieved accuracy level is compared and shown for different frameworks. Finally, we conclude the present challenges and future developments of OMSA.
\end{abstract}

\section{KEYWORDS}

Sentiment Analysis, Opinion Mining, Classification Algorithms, Social Media.

\section{INTRODUCTION}

Opinion Mining and Sentiment Analysis (OMSA) plays a vital role in social media to get positive or negative sentiment and opinions expressed by the user's or public using the mode of online feedback forms, emails and OSN websites such as Facebook, Twitter, LinkedIn, YouTube, MySpace, Blogs and forums etc. Shusen Zhou et al. [14] states that OSN sites are one of the most important tools of the Web 2.0 to share or disseminate views. OMSA helps a lot to predict the product sales, service, quality, policy initiatives, Institutions, forecasting political opinions, and news contents for the company or organization, Government and general public. The main task of OMSA is used to classifying the polarity at the document, sentence, or feature / aspect, and which are expressed as positive, negative or neutral. The sentiment analysis research is also done at this polarity level. The general system architecture of OMSA is constructed as shown Fig. 1, and the main characteristics are analyzed like [1] educational data mining approach and reported performances [12]. This paper is organized as follows. Section 2 presents the recent developments in the field of OMSA with different frameworks and algorithms. Section 3 discusses the obtained results by using datasets and its volume. Section 4 states the challenges and future developments. Finally, Section 5 concludes the paper.

David C. Wyld et al. (Eds) : SAI, CDKP, ICAITA, NeCoM, SEAS, CMCA, ASUC, Signal - 2014 pp. 21-32, 2014. (C) CS \& IT-CSCP 2014

DOI : $10.5121 /$ csit.2014.41103 


\section{RECENT DEVELOPMENTS IN OMSA}

This section presents the recent development of OMSA approach with different frameworks, methods, techniques, and algorithms. The main characteristics of OMSA approach is shown in Table 1, which gives the complete or overall reference to the researchers and the process is explained below. It is necessary to understand the present work to carry out future work without duplication. First, the various framework and algorithms in opinion mining with data collection approach, pre-processing stage and classification of polarity. Second, describes the various framework and algorithms in sentiment analysis with data collection approach, pre-processing stage and classification of polarity.

\subsection{Twitter Opinion Mining (TOM) Frame work and Polarity Classification Algorithm}

Farhan Hassan Khan et al. [5] proposed a new TOM framework to predict the polarity of words into positive or negative feelings in tweets, and to improve the accuracy level of this classification. TOM framework is constructed into three stages. First, data acquisition process, which is used to obtain the Twitter feeds with sparse features through Twitter streaming API from OSN. Twitter4J library has been used to extract only English language tweets. Second, preprocessing, which process each tweets individually for the refinement operations such as detection and analysis of slangs/abbreviations, Lemmatization and correction, and stop words removal. Then the refined tweets pass into the classifier. Third, Polarity Classification Algorithm (PCA), it classifies the twitter feeds on basis of Enhanced Emoticon Classifier (EEC), Improved Polarity Classifier (IPC), and SentiWordNet Classifier (SWNC) by using set of emoticons, a list of positive and negative words, and SentiWordNet dictionary respectively. In this stage, reducing the number of neutral tweets is the major issue. For this problem, final classification is performed to indicate more accurate results than its predecessors based on the scores of EEC, IPC, and SWNC.

\subsection{Standard election prediction model by using User Influence factor}

Malhar Anjaria et al. [10] introduced a model to predict the election result by applying the user influence factor (re-tweets and each party garners) and extracting opinions using direct and indirect feature on the basis of the supervised algorithms such as NB (simple probabilistic model), MaxEnt (Uniform classification model), SVM (achieves maximum margin hyper plane), ANN (feed forward network), and SVM with PCA (dimension reduction). This model is built into several steps. Step1, data collection approach is used to collect tweets with Candidate's name. Step2, normalization and feature reduction includes the refinement operations Internet acronyms and emoticons, duplicate tweets, candidate accounts, word expansion, URLs, repeated words and repeated characters for to get original sentence format into usable format of tweets. Step3, feature extraction and extended terms used for the purpose of unigram, bigram and a unigram + bigram. Step4, machine learning methods, in which the polarity based classification applied to independent features, and it fails to capture query specific sentiments so that the aforementioned text classification algorithms used for direct features. Setp5, incorporating sentiment analysis considers re-tweets into account for influence factor. In Step6, analyzing gender based votes based on term frequency. Finally, US Presidential Election result 2012 and Karnataka State Assembly Election 2013 results are shown that Twitter provides a reasonable accuracy. 


\subsection{Similarity shaped membership function}

Tapia-Rosero A et al. [15] employed a method to detect similarity shaped membership functions in group decision making process. This method is constructed by using the symbolic notation, similarity measure, and grouping membership functions by shape similarity. The symbolic notation has two component algorithms to get shape-string and feature-string which represent a sequence of symbols and sequence of linguistic terms respectively for each segment of membership functions. The similarity measure used the linguistic terms from extremely short to extremely long to obtain an overall similarity at unit interval. In a group decision making environment, the grouping membership functions by shape similarity aims to gather groups using similarity matrix.

\subsection{Three-level similarity method (TLSM)}

Jun ma et al. [8] stated a method to reduce the chance of applying inappropriate decisions in the multi-criteria group decision making (MCGDM). In this aspect, a Gradual Aggregation Algorithm (GAA) developed and established a TLSM. GAA faced two practical issues. First, how to handle missing values. Second, how to generate a decision dynamically in MCGDM?. To solve these issues, GAA is implemented in two ways, i.e., OGA (ordinary gradual algorithm) and WGA (weighted gradual algorithm). The OGA does not explicitly process the criteria weights and leaves it to the aggregation operator but the WGA does. TLSM will be measuring the similarity of two participants opinion at three sequence levels, i.e., assessment level, criterion level, and problem level. In Level-1, the term set will be divided into several semantic-equal groups for the criterion and then used HCFSM. In Leve-2, identifies an appropriate SUF for each criterion at PSA and PRW. In Level-3, each individual criterion provides a single perspective to observe similarity of two opinions.

\subsection{Unsupervised dependency analysis-based approach}

Xiaolin Zheng et al. [17] presented an unsupervised dependency analysis-based approach to extract AEP (Appraisal Expression Pattern) from reviews. The problem statement is defined at different terminologies such as domain, aspect word, sentiment word, background word, and review. Then the AEP is applied to represent the syntactic relationship between aspect and sentiment words by using Shortest Dependency Path (SDP), Confidence score (CS) and parameter inference. Finally, AEP-LDA (Latent Dirichlet Allocation) model is employed to jointly identify the aspect and sentiment words. It outperforms the base line method when compared to other supervised methods such as LDA, Local-LDA, Standard LDA, AEP-LDA (noAEP).

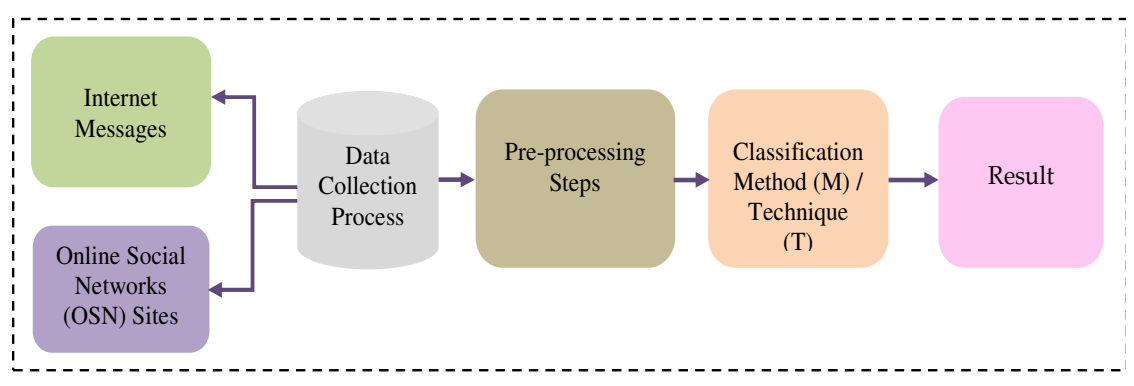

Fig. 1 General System Architecture of OMSA approach 


\subsection{SuperedgeRank algorithm}

Ning Ma et al. [11] introduced a SuperedgeRank algorithm to identify opinion leaders in online public opinion supernetwork model. This model is built up into three stages. First, data processing which identifies the main information from the public comments collected from internet and then applies the ICTCLAS for splitting sentence into words. Second, online public opinion supernetwork modeling includes four types of elements i.e., Social Subnetwork, Environment Subnetwork, Psychological Subnetwork, and Viewpoint Subnetwork to form four layers of supernetwork. Third, Indexes of online public opinion supernetwork includes Node Superdegree, Superedge Degree to identify opinion leaders and Superedge-superedge Distance, and Superedge Overlap to evaluate and verify the results. The aforesaid algorithm ranks the superedges in supernetwork by using the indexes: the influential degree of information dissemination, the transformation likelihood between different psychological types, and the similarity between keywords of viewpoints.

\subsection{Hybrid opinion mining framework for e-commerce application}

Vinodhini $G$ et al. [16] introduced two frameworks by the combination of classifiers with principal component analysis (PCA) to reduce the dimension of feature set. First, PCA with Bagging which is used to construct each member of the ensemble, and to predict the combination over class labels. Second, Bayesian boosting model is employed using rapid miner tool. For data pre-processing, a word vector representation of review sentences is created for the aforesaid models. Finally, the results proved that the PCA is a suitable dimension reduction method for bagged SVM and Bayesian boosting methods.

\subsection{Opinion mining model for ontologies}

Isidro Penalver-Martinez et al. [7] presented an innovative method called ontology based opinion mining to improve the feature-based opinion mining by employing the ontologies in selection of features and to provide a new vector analysis-based method for sentiment analysis. The framework composed by four main modules namely, NLP module, Ontology-based feature identification module, polarity identification module, and opinion mining module. In module1, obtains the morphologic and syntactic structure of each sentence by including the pre-processing and POS. In module2, extract the features from the opinions expressed by users. In module3, provides the positive, negative and neutral values of nouns, adjectives and verbs. In module4, the vector analysis enables an effective feature sentiment classification. Each feature is represented using three coordinates. Finally, the results obtained in the movie review domain.

\subsection{Sentiment extraction and change detection}

Alvaro Ortigosa et al. [2] introduced a new method is called sentiment extraction and change detection. The method includes the operations for extracting sentiments from texts are preprocessing, segmentation into sentences, tokenization, emotion detection, interjection detection, token score assignation (building the lexicon, removing the repetitive letters, spell checking), syntactical analysis, polarity calculation, and for sentiment change detection are building the user regular patter and then comparing weeks. In this aspect, a Facebook application is implemented in SentBuk, which obtains the data from Facebook with the following permissions: Offline_access, Read_stream, and User_about_me and using the user interface performs user regular pattern and combining weeks for classification. 


\subsection{Semi-supervised Laplacian Eigenmap (SS-LE)}

Kyoungok Kim et al. [9] presented SS-LE to reduce the dimensionality of the data points. The experimental process is taken into text cleaning, text refinement, vectorization, applying PCA, and applying SS-LE to reduce the dimension to 2 or 3. SS-LE constructs the graph by utilizing label information and without label information. From this two graphs, graph laplacian matrices are calculated separately, and then dimensionality reduction process used to minimize the distance between two data points and its neighbors by weights.

\subsection{Three ensemble methods with five learners in Facebook application}

Gang Wang et al. [6] conducted the comparative assessment to measure the performance of three ensemble methods i.e., Bagging, Boosting, and Random Subspace with five learners: NB which is a simple probabilistic classification method, MaxEnt doesn't make any assumptions in relations between features, Decision Tree is a sequence model for a sequence of simple tests, K-Nearest Neighbor classifies majority of its vote of its neighbors, and SVM has ability to model nonlinearity. For the above mentioned three ensemble methods, the base learners are constructed from the training data set using random independent, weighted versions, and random subspaces of the feature space respectively.

\subsection{VIKOR and Sentiment Analysis framework}

Daekook Kang et al. [4] presented a new framework in two stages by combining the VIKOR approach and sentiment analysis for measurement of customer satisfaction in mobile services. VIKOR is a compromising ranking method for MCDM. First, data collection and pre-processing stages involves into the operations like preprocessing data from relevant website. Second, compiling dictionaries of service attributes and sentiment words, it combines the dictionary of attributes and dictionary of sentiment words, and then expressed in verb phrases, adjective phrases and adverbial phrases for sentiment words into positive, negative and neural polarity, at the last assigns score with WordNet. Third, the constructed keyword vectors of customer's opinions with reference to the dictionaries. Fourth, the customer satisfaction is measured with respect to each service attribute. Finally, evaluates the customer satisfaction by considering all attributes.

\subsection{Fuzzy deep belief network}

Shusen Zhou et al. [14] constructed a two step semi- supervised learning method for the sentiment classification. In this sense, the general DBN is trained by using abundant unlabeled and labeled reviews, design a fuzzy membership function for each class of reviews, and then DBN maps each review into the output space for constructing the FDBN. In the first step, all unlabeled and labeled reviews trained by using the general DBN and estimate the parameters based on mapping results of all reviews. In second step, all unlabeled and labeled reviews trained based on membership functions. Also, AFD proposed by combining active learning with FDBN for labeling and uses them for training.

\subsection{Construction of constrained domain-specific sentiment lexicon}

Sheng Huang et al. [13] proposed an automatic construction strategy of domain specific sentiment lexicon based on constrained label propagation. In this method, each steps presented sequentially as follows. In step1, sentiment term extraction, which is used to detect and extract candidate term from the corpus. In this step, nouns and noun phrases are expressing objective states, adjectives, 
verbs and their phrases are used for reviewed objects, adverbs and their phrases are used to enhance or weaken the adjectives and verbs opinions. In step2, sentiments seeds extraction, which maintains consistent sentiment polarities across multiple domains and it extracted from semistructured format i.e., Title, Pros, Cons, and Text. It describes rated aspect, positive and negative aspect (nouns and adjective-noun phrases) respectively. In step3, association similarity graph construction, which constructs similarity graph to propagate sentiment information. In step4, constraints definition and extraction focused two types of constraints called contextual constraint and morphological constraint. In contextual constraint, coherence or incoherence relations are used to maintain sentiment polarity directly or reversely. In morphological constraint, coherence or incoherence relations between sentiment terms and also maintains sentiment polarity directly or reversely. In step5, constraint propagation defines a matrix and encodes the direct and reverse constraints into pair-wise constraints. In step6, constrained label propagation in which each sentiment term receives sentiment information from its neighbors and retains its initial polarity label.

Table 1. Main characteristics of OMSA approach published in 2014.

\begin{tabular}{|c|c|c|c|c|c|c|}
\hline $\begin{array}{l}\text { Rof. } \\
\text { No. }\end{array}$ & $\begin{array}{l}\text { OMSA } \\
\text { approach yaxr }\end{array}$ & Discipline & Model & Task & Metbod (M) / Technique (T) & $\begin{array}{l}\text { Alsorithm (A)/Equation(E) } \\
\text { Frame (F) }\end{array}$ \\
\hline$[2]$ & $\begin{array}{l}\text { Alvaro Ortigosa } \\
\text { at al, } 2014\end{array}$ & $\begin{array}{l}\text { Machine } \\
\text { Losaing }\end{array}$ & Descriptive & Clanification & M: SeutBuk & $\begin{array}{l}\text { E: Wookly user voctor, } \\
\text { Enclidesm distance vector, } \\
\text { Distance betwoen wookly } \\
\text { profiles }\end{array}$ \\
\hline [3] & $\begin{array}{l}\text { Arturo } \\
\text { Montajo-Raoz } \\
\text { at al, 2014 }\end{array}$ & $\begin{array}{l}\text { Maching } \\
\text { Learning }\end{array}$ & Descriptive & Clansification & $\begin{array}{l}\text { M: Parnouslized Page Rank } \\
\text { Vectors (PPVa) }\end{array}$ & $\begin{array}{l}\text { A: Random wall algorithm, } \\
\text { E: final ostimate }\end{array}$ \\
\hline$[4]$ & $\begin{array}{l}\text { Daelkook Kang } \\
\text { at al, } 2014\end{array}$ & $\begin{array}{l}\text { Machine } \\
\text { Learaing }\end{array}$ & Descriptive & Clasification & $\begin{array}{l}\text { M: VIROR ad Sentiment } \\
\text { Analyris }\end{array}$ & $\begin{array}{l}\text { F: Data colloction and } \\
\text { proprocensing, and } \\
\text { measuroment of customer } \\
\text { satisfaction. }\end{array}$ \\
\hline [ร] & $\begin{array}{l}\text { Farhan Hastan } \\
\text { Khan at al. ['] } \\
2014\end{array}$ & $\begin{array}{l}\text { Machine } \\
\text { Learsing }\end{array}$ & Descriptive & Clasification & M: EEC, IPC \& SWNC & $\begin{array}{l}\text { A: Polarity Claskification } \\
\text { Algorithm }\end{array}$ \\
\hline [6] & $\begin{array}{l}\text { Gang Wing of } \\
\text { al, } 2014\end{array}$ & $\begin{array}{l}\text { Machine } \\
\text { Learning }\end{array}$ & Descriptive & Clasification & $\begin{array}{l}\text { M: Bagging, Boosting, and } \\
\text { Random Subrpace, NB, } \\
\text { MaxFur, Decision Treo, } \mathrm{K}- \\
\text { Nenrost naighbor, and SVM }\end{array}$ & $\begin{array}{l}\text { A: Bagging Algorithm, } \\
\text { Adaboost algoritum Radom } \\
\text { Subapace algorithm }\end{array}$ \\
\hline$[7]$ & $\begin{array}{l}\text { Isidro } \\
\text { Pousalver- } \\
\text { Martinez ot al. } \\
2014\end{array}$ & $\begin{array}{l}\text { Machine } \\
\text { Learaing }\end{array}$ & Descriptive & Clasification & M:N-Gram & E: Neratral Sense \\
\hline$[8]$ & $\begin{array}{l}\ln \mathrm{Ma}_{\mathrm{a}} \text { ot al., } \\
2014\end{array}$ & $\begin{array}{l}\text { Machine } \\
\text { Lasming }\end{array}$ & Descriptive & Similarity & $\begin{array}{l}\text { T: Hiarachical clustoring } \\
\text { M: TLSM (Asrewnment } \\
\text { lorol, Problem lovel and } \\
\text { critorion levol) }\end{array}$ & $\begin{array}{l}\text { A: Gradual Aggrogation } \\
\text { Algorithm (GAA) }\end{array}$ \\
\hline [9] & $\begin{array}{l}\text { Kyoungok Kim } \\
\text { at al, } 2014\end{array}$ & $\begin{array}{l}\text { Machine } \\
\text { Losming }\end{array}$ & Descriptive & Clasification & $\begin{array}{l}\text { M: Somi-mpervined } \\
\text { dimenoiouslity redaction }\end{array}$ & $\begin{array}{l}\text { A: Semi-rapervibed Laplacian } \\
\text { aiganmoph, }\end{array}$ \\
\hline [10] & $\begin{array}{l}\text { Malhar Anjaria } \\
\text { at al, } 2014\end{array}$ & $\begin{array}{l}\text { Machine } \\
\text { Leasming }\end{array}$ & Predictivo & Clanification & $\begin{array}{l}\text { M: NB, MaxFnt, SVM, } \\
\text { ANN, SVM with PCA }\end{array}$ & $\begin{array}{l}\text { A: Prodicting outcome of an } \\
\text { Electoral Poll with Modified } \\
\text { axtanded festuros, and feed } \\
\text { forward network training by } \\
\text { back propagaticn lesring }\end{array}$ \\
\hline [11] & $\begin{array}{l}\text { Ning Ma ot al., } \\
2014\end{array}$ & $\begin{array}{l}\text { Machine } \\
\text { Lesming }\end{array}$ & Descriptive & Clasification & $\begin{array}{l}\text { I: Corrolstion analyyis } \\
\text { amoug superedges }\end{array}$ & A: SuperodgeRank algorithm \\
\hline [13] & $\begin{array}{l}\text { Shong Huning ot } \\
\text { al, } 2014\end{array}$ & $\begin{array}{l}\text { Machine } \\
\text { Learaing }\end{array}$ & Descriptive & Clanification & $\begin{array}{l}\text { T: Awocistion similarity } \\
\text { greph construction }\end{array}$ & $\begin{array}{l}\text { A: Conatrint propagation } \\
\text { algorithm }\end{array}$ \\
\hline [14] & $\begin{array}{l}\text { Shroan Zhon ot } \\
\text { al., } 2014\end{array}$ & $\begin{array}{l}\text { Machine } \\
\text { Learning }\end{array}$ & Descriptive & Clasification & $\begin{array}{l}\text { M: Furry desp belief } \\
\text { networks (FDBN) }\end{array}$ & $\begin{array}{l}\text { A: FDBN Algorithm, AFD } \\
\text { Algorithm }\end{array}$ \\
\hline [15] & $\begin{array}{l}\text { Tryin-Rosaro A } \\
\text { at al, } 2014\end{array}$ & $\begin{array}{l}\text { Machine } \\
\text { Lesming }\end{array}$ & Descriptive & Similarity & $\begin{array}{l}\text { M: Symbolie notation and } \\
\text { Similarity moasure }\end{array}$ & $\begin{array}{l}\text { A: getShypeString Algorithm } \\
\text { and gotfoutureString } \\
\text { Algorithm }\end{array}$ \\
\hline [16] & $\begin{array}{l}\text { Vinodhini G ot } \\
\text { al, } 2014\end{array}$ & $\begin{array}{l}\text { Machine } \\
\text { Learning, } \\
\text { Statistical }\end{array}$ & Predictivo & Clanification & $\begin{array}{l}\text { T: PCA with Bugging and } \\
\text { PCA with Booting }\end{array}$ & $\begin{array}{l}\text { A: Bayosian Boosting } \\
\text { algorithm }\end{array}$ \\
\hline [17] & $\begin{array}{l}\text { Xisolin Zhong } \\
\text { ot al, } 2014\end{array}$ & $\begin{array}{l}\text { Machine } \\
\text { Leaning. } \\
\text { Probsbility }\end{array}$ & Descriptive & Clasification & $\begin{array}{l}\text { M: Nearent mothod and } \\
\text { Mutual information method }\end{array}$ & $\begin{array}{l}\text { E: Topic asvigments for all } \\
\text { senteace F: Depandency } \\
\text { graph of sautauce }\end{array}$ \\
\hline
\end{tabular}




\subsection{Ranked WordNet graph for sentiment polarity}

Arturo Montejo-Raez et al. [3] employed a method for sentiment classification by using weights of WordNet graph. In this method, the polarity of measurement consider in the interval $[-1,1]$ and defines a function where values over zero refers positive polarity, values below zero refers negative polarity and values to closer to zero refers neutral. This function is computed by expanding senses and final estimation. Expanding senses intends to expand few concepts in order to calculate the global polarity of the tweet by using the graph of WordNet according to random walk algorithm. The final estimation i.e., final polarity score is evaluated by the combination of SentiWordNet score and random walk weights.

\section{EVALUATION RESUlTS OF OMSA APPROACH}

The OMSA approaches are demonstrated in particular resources with different datasets and its volume as stated in Table 2. Also, the evaluated classification performance was analyzed by using the feature selection process with the different types of metrics such as confusion matrices, precision, recall and F-measure, etc., and their key findings in all the OMSA approach as shown in Table 3. In this paper, we have used the Polarity Classification Algorithm (PCA) and evaluation procedure to verify the accuracy for the above mentioned approach by using the Sanders-Twitter Sentiment Corpus [18]. The corpus contained 5513 hand-classified tweets which are focused on the topic of the companies (Apple, Google, Microsoft and Twitter) and products. The tweet sentiments are labeled as positive, neutral, negative and irrelevant. The datasets count is given in Table 4. These datasets has been measured with 43 trained tweets by using the confusion matrices (Table 5), precision, recall, F-measure and accuracy. The results are shown in Table 6 and Figure 2. In this analysis, the overall system accuracy is only considered and shown.

Table 4. Dataset count

\begin{tabular}{|l|c|}
\hline Datasets & No. of. Tweets \\
\hline Apple & 1313 \\
\hline Google & 1381 \\
\hline Microsoft & 1415 \\
\hline Twitter & 1404 \\
\hline
\end{tabular}

Table 5. Confusion matrix

\begin{tabular}{|c|c|c|c|c|}
\hline & $\mathrm{P}$ & $\mathrm{Q}$ & $\mathrm{R}$ & $\mathrm{S}$ \\
\hline $\mathrm{P}$ & $\mathrm{tpP}$ & $\mathrm{ePQ}$ & $\mathrm{ePR}$ & $\mathrm{ePS}$ \\
\hline $\mathrm{Q}$ & $\mathrm{eQP}$ & $\mathrm{tpQ}$ & $\mathrm{eQR}$ & $\mathrm{eQS}$ \\
\hline $\mathrm{R}$ & $\mathrm{eRP}$ & $\mathrm{eRQ}$ & $\mathrm{tpR}$ & $\mathrm{eRS}$ \\
\hline $\mathrm{S}$ & $\mathrm{eSP}$ & $\mathrm{eSQ}$ & $\mathrm{eSR}$ & $\mathrm{tpS}$ \\
\hline
\end{tabular}

Precision $\mathrm{P}=\mathrm{tpP} /(\mathrm{tpP}+\mathrm{eQP}+\mathrm{eRP}+\mathrm{eSP})$, Recall $\mathrm{P}=\mathrm{tpP} /(\mathrm{tpP}+\mathrm{ePQ}+\mathrm{ePR}+\mathrm{ePS}), \mathrm{F}-$ measure $=2 \mathrm{x}$ $($ Precision $\mathrm{x}$ Recall $) /($ Precision + Recall $)$, Accuracy $=($ True Positive + True Negative + True Neutrals + True irrelevant) $/$ (True Positive + False Positive + True Negative + False Negative + True Neutrals + False Neutrals + True Irrelevant + False Irrelevant). Based on this results and observations, the accuracy level of the OMSA approach remains the same for the resources. 
Table 2. Results of OMSA approach with datasets and key findings

\begin{tabular}{|c|c|c|c|c|c|}
\hline $\begin{array}{l}\text { Rof. } \\
\text { No. }\end{array}$ & $\begin{array}{l}\text { OMSA } \\
\text { approsch your }\end{array}$ & Resources & Datasets & Volume & Koy Finding: \\
\hline$[2]$ & $\begin{array}{l}\text { Alvaro } \\
\text { Ortigosa of al., } \\
2014\end{array}$ & Facebook & Facobook & $\begin{array}{l}1000 \text { for wach class } \\
\text { (poxitive, negativo or } \\
\text { neutral) }\end{array}$ & $\begin{array}{l}\text { Users' sentimeant polarity } \\
\text { oxtracted and modelad to detect } \\
\text { omotional chrages }\end{array}$ \\
\hline [3] & $\begin{array}{l}\text { Arturo } \\
\text { Montojo-Raoz } \\
\text { et al, } 2014\end{array}$ & Twittor & - & $\begin{array}{l}376,296 \text { troets - } 181,492 \\
\text { positive, } 194,804 \\
\text { negative }\end{array}$ & $\begin{array}{l}\text { Sentimont polarity clasification } \\
\text { in Twittor posts by uning } \\
\text { woightod nodes and WordNet } \\
\text { guph }\end{array}$ \\
\hline$[4]$ & $\begin{array}{l}\text { Daokook Kang } \\
\text { at al, } 2014\end{array}$ & $\begin{array}{l}\text { Alpp Store- } \\
\text { AlppStore HQ }\end{array}$ & $\begin{array}{l}\text { Bump, Facebook, } \\
\text { Fouruquare, Fring, } \\
\text { Googlet, Skype, } \\
\text { Twitter, Word Press }\end{array}$ & $\begin{array}{l}\text { 1487 Reviews from } 8 \\
\text { mobile app services, } 166 \text {, } \\
303,144,112,152,231 \text {, } \\
271,108\end{array}$ & $\begin{array}{l}\text { Customar satiafaction measurod } \\
\text { for mobile services by combining } \\
\text { VIKOR and Sentiment Amalywis. }\end{array}$ \\
\hline [ร] & $\begin{array}{l}\text { Farhan Hassan } \\
\text { Khom at al, } \\
2014\end{array}$ & Twittor & Twitter & $\begin{array}{l}\text { 6(2116-Random } \\
\text { Troets) }\end{array}$ & $\begin{array}{l}\text { Improved the accuracy of } \\
\text { classification wing Twitter } \\
\text { Opining Mining (TOM) } \\
\text { famswork }\end{array}$ \\
\hline [6] & $\begin{array}{l}\text { Gang Wang ot } \\
\text { al., } 2014\end{array}$ & $\begin{array}{l}10 \text { public SA } \\
\text { datasets }\end{array}$ & $\begin{array}{l}\text { Camera, Camp, } \\
\text { Doctor, Drug, Laptop, } \\
\text { Lawyer, Movio, } \\
\text { Maric, Radio, TV }\end{array}$ & $\begin{array}{l}250: 248,402: 402, \\
739: 739,401: 401,88: 88, \\
110: 110,1000: 1000, \\
291: 291,502: 502,235: 235\end{array}$ & $\begin{array}{l}\text { Comparative ascassment } \\
\text { conducted for thros onsemble } \\
\text { mothods with frve learsers }\end{array}$ \\
\hline$[7]$ & $\begin{array}{l}\text { Ividro } \\
\text { Ponalver- } \\
\text { Martinez ot al. } \\
2014\end{array}$ & Internot messusges & Movie Ontology & Movie reviews & Ontology based opinion mining \\
\hline [8] & $\begin{array}{l}\text { Jun Ma ot al. } \\
2014\end{array}$ & $\begin{array}{l}\text { Social Policy, } \\
\text { Energy Policy }\end{array}$ & - & $\begin{array}{l}6 \text { Social actors for } 7 \\
\text { possible polices } \\
3 \text { Energy policien for } 6 \\
\text { domain experts }\end{array}$ & 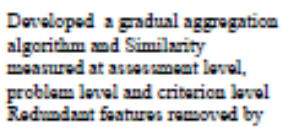 \\
\hline [9] & $\begin{array}{l}\text { Kyoungok } \\
\text { Kim ot al.. } \\
2014\end{array}$ & Internot messages & $\begin{array}{l}\text { Book, DVD, } \\
\text { Electronics, and } \\
\text { Kitcban }\end{array}$ & $\begin{array}{l}1000 \text { positivo and } 1000 \\
\text { nogativo rvijews for } \\
\text { osch domain }\end{array}$ & $\begin{array}{l}\text { applying Semi-superised } \\
\text { Laplacion aigoumsp (SS-LE) and } \\
\text { onsbled visuslization of } \\
\text { documents }\end{array}$ \\
\hline [10] & $\begin{array}{l}\text { Malhar } \\
\text { Argaria ot al. } \\
2014\end{array}$ & Twittor & $\begin{array}{l}\text { US Prosidautial } \\
\text { Election } 2012 \text { result } \\
\text { Twoets, } \\
\text { Rarnatala State } \\
\text { Ansably Election } \\
2013 \text { result troets }\end{array}$ & 25000 & $\begin{array}{l}\text { Outcoms of an election revalt } \\
\text { prodicted based on Uner } \\
\text { inflence factor and extracted } \\
\text { opimions ming direct and indirect } \\
\text { feature }\end{array}$ \\
\hline [11] & $\begin{array}{l}\text { Ning Ma ot al., } \\
2014\end{array}$ & Tixmya Club & $\begin{array}{l}\text { Japan's muclosz } \\
\text { laskage accidant }\end{array}$ & $\begin{array}{l}1019 \text { posts by } 671 \\
\text { participants }\end{array}$ & $\begin{array}{l}\text { Opinion lesdens identified in } \\
\text { vugpornotwork malysis }\end{array}$ \\
\hline [13] & $\begin{array}{l}\text { Shong Huang } \\
\text { ot al, } 2014\end{array}$ & $\begin{array}{l}\text { Epiniona.com } \\
\text { Tripadrisor ad } \\
\text { Edmunds. }\end{array}$ & Cars \& Hotals & $\begin{array}{l}972,988 \& \\
42.288 \\
254.539\end{array}$ & $\begin{array}{l}\text { Automatic construction strassg } \\
\text { for domain-spocific seatimsat } \\
\text { laxicon }\end{array}$ \\
\hline [14] & $\begin{array}{l}\text { Shusan Zbon } \\
\text { at al, } 2014\end{array}$ & Internet mencages & $\begin{array}{l}\text { MOV, BOO, DVD, } \\
\text { FLE, KIT }\end{array}$ & $\begin{array}{l}1000 \text { positivo and } 1000 \\
\text { negative rvviems for } \\
\text { oxch datasot }\end{array}$ & $\begin{array}{l}\text { Constructed FDBN architecture } \\
\text { for intprorvd classification } \\
\text { performence }\end{array}$ \\
\hline [15] & $\begin{array}{l}\text { Tayia-Ronero } \\
\text { A at al, } 2014\end{array}$ & $\begin{array}{l}\text { Symbbolic } \\
\text { Notations }\end{array}$ & $\begin{array}{l}\text { Shape - symbolic } \\
\text { notation }\end{array}$ & 120 & $\begin{array}{l}\text { Identified similarity absped } \\
\text { mambarihip fumctions from the } \\
\text { large groug of exparts }\end{array}$ \\
\hline [16] & $\begin{array}{l}\text { Vinodhini G ot } \\
\text { al., } 2014\end{array}$ & Internot mensages & Product reviaws & $\cdot$ & $\begin{array}{l}\text { PCA with Bagging, PCA with } \\
\text { Boosting }\end{array}$ \\
\hline [17] & $\begin{array}{l}\text { Xisolin Zheng } \\
\text { at al, } 2014\end{array}$ & $\begin{array}{l}\text { Triphdtriser, } \\
\text { Amason com }\end{array}$ & $\begin{array}{l}\text { Revtarunant, Hotel, } \\
\text { MP3 } \\
\text { Crmera }\end{array}$ & 2000 (from sach domain) & $\begin{array}{l}\text { Appraisal Exprousion Pattorns } \\
\text { (AFP) oxtractod to roprovent } \\
\text { syatactic rolations. Aspect and } \\
\text { sentiment words jointly } \\
\text { indentified by using AFP-IDA } \\
\text { model }\end{array}$ \\
\hline
\end{tabular}


Table 6. Dataset calculation for confusion matrices, precision, recall and accuracy

\begin{tabular}{|c|c|c|c|c|c|c|c|c|c|}
\hline & & \multicolumn{4}{|c|}{ Confusion Matrices } & \multicolumn{4}{|c|}{ Results } \\
\hline \multicolumn{2}{|c|}{ Data Sets } & Positive & Negative & Neutral & Irrelevant & $\begin{array}{c}\text { Precision } \\
(\%)\end{array}$ & Recall (\%) & $\begin{array}{c}\text { F-measure } \\
(\%)\end{array}$ & $\begin{array}{c}\text { Accuracy } \\
(\%)\end{array}$ \\
\hline \multirow{4}{*}{ Apple } & Positive & 182 & 3 & 6 & 7 & 94.79 & 91.92 & 93.33 & \multirow{4}{*}{96.73} \\
\hline & Negative & 7 & 367 & 5 & 3 & 97.09 & 96.07 & 96.58 & \\
\hline & Neutral & 2 & 5 & 567 & 1 & 98.10 & 98.61 & 98.35 & \\
\hline & Irrelevant & 1 & 3 & 0 & 154 & 93.33 & 97.47 & 95.36 & \\
\hline \multirow{4}{*}{ Google } & Positive & 209 & 3 & 6 & 7 & 95.43 & 92.89 & 94.14 & \multirow{4}{*}{96.89} \\
\hline & Negative & 7 & 51 & 5 & 3 & 82.26 & 77.27 & 79.69 & \\
\hline & Neutral & 2 & 5 & 590 & 1 & 98.17 & 98.66 & 98.42 & \\
\hline & Irrelevant & 1 & 3 & 0 & 488 & 97.80 & 99.19 & 98.49 & \\
\hline \multirow{4}{*}{ Microsoft } & Positive & 84 & 3 & 6 & 7 & 89.36 & 84.00 & 86.60 & \multirow{4}{*}{96.96} \\
\hline & Negative & 7 & 128 & 5 & 3 & 92.09 & 89.51 & 90.78 & \\
\hline & Neutral & 2 & 5 & 657 & 1 & 98.35 & 98.80 & 98.57 & \\
\hline & Irrelevant & 1 & 3 & 0 & 503 & 97.86 & 99.21 & 98.53 & \\
\hline \multirow{4}{*}{ Twitter } & Positive & 65 & 3 & 6 & 7 & 86.67 & 80.25 & 83.33 & \multirow{4}{*}{96.93} \\
\hline & Negative & 7 & 68 & 5 & 3 & 86.08 & 81.93 & 83.95 & \\
\hline & Neutral & 2 & 5 & 627 & 1 & 98.28 & 98.74 & 98.51 & \\
\hline & Irrelevant & 1 & 3 & 0 & 601 & 98.20 & 99.34 & 98.77 & \\
\hline
\end{tabular}
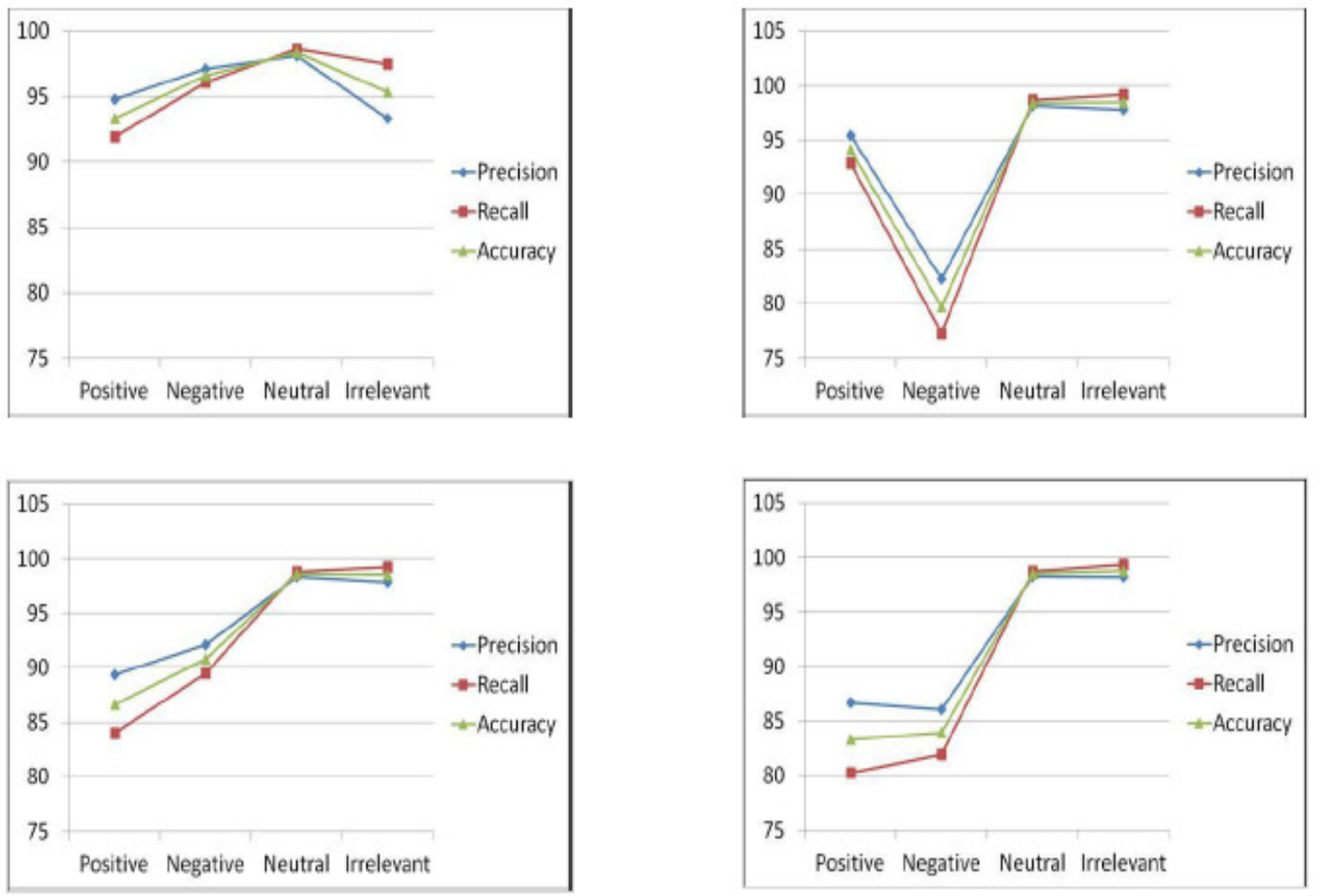

Figure 2. Comparing precision, recall, F-measure and accuracy with four different datasets 


\section{DisCUSSED CHALLENGES AND FUTURE DEVELOPMENTS IN OMSA}

The challenges and future developments are discussed below for the above presented frameworks of OMSA approach published in 2014. It is one of the important tools to the aspirant researchers to focus on new innovative idea. Farhan Hassan Khan et al. [5] indicated that TOM framework faced challenges due to their short length and irregular structure of the content such as named entity recognition, anaphora resolution, parsing, sarcasm, sparsity, abbreviations, poor spellings, punctuation and grammar, incomplete sentences. Also, suggested to compare the proposed algorithm with TweetFeel and Sentiment 140 for further improvement of the accuracy. Malhar Anjaria et al. [10] mentioned that the presence of all entities in unbiased and equal manner was the biggest challenge to provide the accuracy in the standard election prediction model. But, there is a chance of increasing the accuracy level in future by including the more influential factors as age, educational background, employment, economic criterion, rural and urban and social development index.

Tapia-Rosero A et al. [15] discussed that the group decision making process might be difficult under a supervision of mediator. This work could be extended to final objectives i.e., strategic planning, suitability analysis, and applications like fuzzy control, fuzzy time series to find the similarities. Jun ma et al. [8] indicated the major issues that to reduce the risk of putting an inappropriate decision making and measuring opinion similarity between the participants. In GAA, the integrating information according to group of inputs and missing value and unclear answers need to be studied in future. Xiaolin Zheng et al. [17] stated that to jointly identify aspect and sentiment word with comparison of other models. In future work, AEP-LDA model to assume at single sentence and extend at clause level and into aspect-based review summarization, sentiment classification, and personalized recommendation systems.

Ning Ma et al. [11] discussed that online public opinion controlled by deleting long existing posts with rumor from negative opinion leaders. After identifying the opinion leaders, the further work should be focused on how to implement corresponding guidance and interference. Vinodhini G et al. [16] misclassification is reduced, and the classification accuracy of negative opinion to be improved. Isidro Penalver-Martinez et al. [7] addressed the present challenges that ontologybased feature identification, and feature polarity identification. Alvaro Ortigosa et al. [2] demonstrated to extract information from user messages and detect emotional changes. Further, tests to be conducted to determine the values in each case for sentiment changes, and the threshold to distinguish between small changes on user sentiment and significant changes.

Kyoungok Kim et al. [9] addressed the dimensionality reduction transformations into 2D or 3D by using term frequency matrices, and further work suggested that the weight of the edges in the label graph will be adjusted by using the sophisticated approach and to transform document into term frequency. Gang Wang et al. [6] evaluated the ensemble methods, and specified that large datasets need to be collected for validating the result in future i.e., improving the interpretability of ensembles is an important research direction. Daekook Kang et al. [4] indicated that the measurement of the customer satisfaction was conducted by surveys. It's taken more time and effort to collect useful information. Further studies suggested that to incorporate more advanced techniques of sentiment analysis and validate the empirical results presented.

Shusen Zhou et al. [14] discussed the issues that embed the fuzzy knowledge to improve the performance of semi-supervise based sentiment classification. Sheng Huang et al. [13] incorporated the contextual and morphological constraints between sentiment terms, and suggested the future works that incorporate more types of constraints knowledge between sentiment terms and to distinguish the aspect-specific polarities. Arturo Montejo-Raez et al. [3] 
stated that how to deal with negation, and to study the context of a specific tweet among the time line of tweets from the particular user in order to identify publisher's mood and adjust final score.

Table 3. Performance Analysis of OMSA approach using feature extraction

\begin{tabular}{|c|c|c|c|}
\hline $\begin{array}{l}\text { Ref } \\
\text { No. }\end{array}$ & OMSA approach year & $\begin{array}{l}\text { Performance Analysis by using feature extraction } \\
\text { Types of Metrics }\end{array}$ & Accuracy $(\%)$ \\
\hline [2] & Alvaro Ortigosa et al., 2014 & $\begin{array}{l}\text { Evaluating lexicon-based approach with all the messages, Evaluating } \\
\text { lexicon-based approach with status messages, Evaluating machine } \\
\text { learning approaches and hybrid solutions }\end{array}$ & 83.27 \\
\hline [3] & $\begin{array}{l}\text { Arturo Montejo-Raez et } \\
\text { al., } 2014\end{array}$ & Using Support Vector Machine (RW-SVM). Precision, Recall, F1 & $\begin{array}{l}0.6429 \\
0.6147 \\
0.6285\end{array}$ \\
\hline [4] & Daekook Kang et al, 2014 & Maximum group utility and minimum individual regret & - \\
\hline$[5]$ & $\begin{array}{l}\text { Farhan Hassan Khan et al., } \\
2014\end{array}$ & Confusion Matrices, Precision, Recall, F-Measure & 87.5 \\
\hline [6] & Gang Wang et al, 2014 & $\begin{array}{l}\text { Average accuracy by confusion matrix, } 10 \text {-fold cross validation, Five } \\
\text { used base leamers, NB - Simple Probabilistic classification method, } \\
\text { Violated by real-world data, ME, DT, KNN, SVM, Unigram, Bigam, } \\
\text { Term frequency and TF-DF }\end{array}$ & RV-SVM \\
\hline [7] & $\begin{array}{l}\text { Isidro Penalver-Martinez } \\
\text { et al., } 2014\end{array}$ & N_GRAM Before, N_GRAM After, N_GRAM Around, and All Phrase & - \\
\hline [8] & Jun Ma et al., 2014 & Similarity Matrix & - \\
\hline [9] & Kyoungok Kim et al, 2014 & $\begin{array}{l}\text { Sentiment visualization - 2D scatter plots compared by } 6 \text { dimensionality } \\
\text { reduction (PCA. Isomap, t-SNE, LE, SS-MMC, and SS-LE, Sentiment } \\
\text { Classification - predicted accuracy of SVM and k-NN using seven } \\
\text { dimensional reduction methods including SS-LE. }\end{array}$ & $\begin{array}{l}20 \text { slightly better } \\
\text { than SVM }\end{array}$ \\
\hline$[10]$ & Malhar Anjaria et al., 2014 & $\begin{array}{l}\text { Effects of Data Cleansing. Hybrid Model of Unigram and Bigram US-E, } \\
\text { Gender Based Vote, Vote Shared Based KSAE, Sentiment Accuracy. } \\
\text { Comparison for SVM with PCA. Twitter User-USA\& India }\end{array}$ & 88 \\
\hline [11] & Ning Ma et al, 2014 & $\begin{array}{l}\text { Newly evaluation metric formed by Superedge overlap (SO) and } \\
\text { Superedge- superedge distance }\end{array}$ & - \\
\hline [13] & Sheng Huang et al., 2014 & $\begin{array}{l}\text { Chi-scuare based polarity determination, PMI- } \mathbb{R} \text {, Label Propagation, } \\
\text { Micro - and macro- averaged Precision, Recall, F-measure }\end{array}$ & - \\
\hline [14] & Shusen Zhou et al., 2014 & $\begin{array}{l}\text { Performance of flazy deep belief networks, Test accuracy with } 100 \\
\text { labeled reviews for active semi-supervised learning. Performance of } \\
\text { active fuzzy deep belief networks, Active leaming for } 5 \text { iterations, } \\
\text { Experiments with a different number of labeled reviews, and AFD with } \\
\text { AND }\end{array}$ & - \\
\hline [15] & Tapia-Rosero A et al., 2014 & Similarity matrix with dimensions $120 \times 120$, values ranging from 0 to 1 & - \\
\hline [16] & Vinodhini G et al, 2014 & $\begin{array}{l}\text { Compared SVM - Model I with SVM - Model II, SVM, Logistics } \\
\text { regression, Bagged SVM, Bayesian boosting }\end{array}$ & - \\
\hline$[17]$ & Xiaolin Zheng et al., 2014 & $\begin{array}{l}\text { Experimental setup - Fleiss kappa, Analysis of appraisal expression } \\
\text { pattern, Qualitative evaluation by using F-score, Aspect word } \\
\text { identification by using precision, recall. F-score, Sentiment word } \\
\text { identification by Nearest Method and MIM Domain adaptation of AEP } \\
\text { by using Loss measure }\end{array}$ & - \\
\hline
\end{tabular}

Based on this observation, OMSA approach is not following any single algorithm or technique or method for data collection process, pre-processing and classification, and to solve all issues in social media for extracting the user's opinion. Therefore, the problem is defined with some specific application domain to estimate the polarity of the system. The OMSA approach is also dealt with various models as shown in Table 1 such as descriptive, predictive and statistical for the purpose of extracting opinions by using the applications of Fuzzy sets, grouping similarity measure, group decision making process, policy creation process, OSN sites, and symbolic notations. The analysis of result is very useful to overcome issues and to develop various new methods or techniques without duplication. 


\section{CONCLUSION}

Opinion mining and sentiment analysis is emerging as a challenging field as part of text mining in social networks to an organization, Government and public. It has a lot of applications and developments that to predict people's polarity towards their decision making process. In this paper, we conclude that the frameworks and algorithms of OMSA are presented with the data collection process, preprocessing methods, classification and performance evaluation results as a review.

\section{REFERENCES}

[1] Alejandro Pena-Ayala.: Educational data mining: A survey and a data mining-based analysis of recent works. Expert Systems with Applications. 41, 1432-1462 (2014)

[2] Alvaro Ortigosa, Jose M. Martin, Rosa M. Carro.: Sentiment analysis in Facebook and its application to e-learning. Computers in Human Behavior. 31, 527-541 (2014)

[3] Arturo Montejo-Raez, Eugenio Martinez-Camara, M. Teresa Martin-Valdivia, L. Alfonso UrenaLopez.: Ranked WordNet graph for Sentiment Polarity Classification in Twitter. Computer Speech and Language. 28, 93-107 (2014)

[4] Daekook Kang, Yongtae Park.: Review-based measurement of customer satisfaction in mobile service: Sentiment analysis and VIKOR approach. Expert Systems with Applications. 41, 1041-1050 (2014)

[5] Farhan Hassan Khan, Saba Bashir, Usman Qamar.: TOM: Twitter opinion mining framework using hybrid classification scheme. Decision Support Systems. 57, 245-257 (2014)

[6] Gang Wang, Jianshan Sun, Jian Ma, Kaiquan Xu, Jibao Gu.: Sentiment Classification: The contribution of ensemble learning. Decision support systems. 57, 77-93 (2014)

[7] Isidro Penalver-Martinez, Francisco Garcia-Sanchez, Rafael Valencia-Garcia, Miguel Angel Rodriguez-Garcia, Valentin Moreno, Anabel Fraga, Jose Luis Sanchez-Cervantes.: Feature-based opinion mining through ontologies. Expert Systems with Applications. 41, 5995-6008 (2014)

[8] Jun Ma, Jie Lu, Guangquan Zhang.: A three-level-similarity measuring method of participant opinions in multiple-criteria group decision supports. Decision Support Systems. 59, 74-83 (2014)

[9] Kyoungok Kim, Jaewook Lee.: Sentiment visualization and classification via semi-supervised nonlinear dimensionality reduction. Pattern Recognition. 47, 758-768 (2014)

[10] Malhar Anjaria \& Ram Mohana Reddy Guddeti.: Influence factor based opinion mining of twitter data using supervised learning. Sixth IEEE International conference on communication systems and networks (COMSNETS). ISSN: 1409-5982, (2014)

[11] Ning Ma, Yijun Liu.: SuperedgeRank algorithm and its application in identifying opinion leader of online public opinion supernetwork. Expert Systems with Applications. 41, 1357-1368 (2014)

[12] R.V. Vidhu Bhala, S. Abirami.: Trends in word sense disambiguation. Artificial Intelligence Review: An International Science and Engineering Journal. DOI 10.1007/s10462-012-9331-5, Springer, (2012)

[13] Sheng Huang, Zhendong Niu, Chongyang Shi.: Automatic construction of domain-specific sentiment lexicon based on constrained label propagation. Knowledge-Based Systems. 56, 191-200 (2014)

[14] Shusen Zhou, Qingcai Chen, Xiaolong Wang.: Fuzzy deep belief networks for semi-supervised sentiment classification. Neurocomputing. 131, 312-322 (2014)

[15] Tapia-Rosero A, A. Bronselaer, G. De Tre.: A method based on shape-similarity for detecting similar opinions in group decision-making. Information Sciences. 258, 291-311 (2014)

[16] Vinodhini G, Chandrasekaran RM.: Measuring quality of hybrid opinion mining model for ecommerce application. Measurement. 55, 101-109 (2014)

[17] Xiaolin Zheng, Zhen Lin, Xiaowei Wang, Kwei-Jay Lin, Meina Song.: Incorporating appraisal expression patterns into topic modeling for aspect and sentiment word identification. KnowledgeBased Systems. 61, 29-47 (2014)

[18] Niek J. Sanders.: Sanders-Twitter Sentiment Corpus, Version 2.0.1 